\title{
Optimization of the conditions of the extraction and purification stages of the Shilajit substance
}

\author{
Fedor BUGAEV 1 * D , Dmitriy KOMPANTSEV 2 (D) , Lyudmila POGREBNYAK 2 (D) \\ 1 LLC "Kvadrat-S", Moscow, Russian Federation \\ 2 Pyatigorsk Medical and Pharmaceutical Institute - a branch of the Volgograd State Medical University of the Ministry \\ of Health of Russia, Pyatigorsk, Russian Federation
}

* Corresponding Author. E-mail: fedya-bugaev@yandex.ru (F.B.); Tel.+7-951-545 4375.

Received: 21 January 2019 / Revised: 28 March 2019 / Accepted: 23 May 2019

\begin{abstract}
The Shilajit was prepared according to different technologies, depending on the extraction stages, the purification method and the drying method, after which the content of the ballast substances was determined in the obtained samples. For the obtained samples, complete elemental analysis was performed on the S8 Tiger Wave X-ray fluorescence spectrometer. In the course of the experiment, the dependence of the content of ballast silicon ( $\mathrm{Si}$ ) and aluminum (Al) substances was revealed depending on the extraction stages, the purification method, and the drying method. As a result of the research, the optimum technological regime was chosen, observance of which of the Shilajit will be the minimum content of ballast substances.
\end{abstract}

KEYWORDS: Shilajit; production technology; ballast substances; X-ray fluorescence spectrophotometry.

\section{INTRODUCTION}

Shilajit is a complex of natural biologically active substances, macro and micro elements including those with toxic substances[1,2]. Despite the millennial experience of using Shilajit as a remedy, new technologies and innovations have not reduce relevance and are capable of bringing it to a new qualitative level. Considering the tendency of increasing the requirements for substances for the production of dietary supplements (especially in terms of the content of toxic elements, which are abundant in certain deposits of Shilajit from the foreign origin), as well as the need to increase the efficiency of the technological chain, productivity and reduce the production costs. Analyzing the patent database, as well as available sources of scientific literature, we concluded, that at the present time in the production of purified Shilajit the different technological methods are used to increase the yield of biologically active substances with established physiological action (humic acids, fulvic acid) without accenting on processes contributing to a decrease in the share of ballast substances (which potentially should reduce the proportion of toxic substances and heavy metals in the substance used in the technological production of biological active compounds)[3].

The purpose of this work is to select the optimal conditions of technology for obtaining Shilajit, at the extraction and the purification stage, based on the level of ballast substances in the Shilajit.

During the study, the influence of the spray drying method, ultrasonic cavitation for the extraction and centrifugation stage on the content of ballast substances such as silicon (Si) and aluminum (Al) was first revealed.

\section{RESULTS AND DISCUSSION}

As a result of the study, the dependence of the content of ballast substances on the ratio of raw material and the extractant, application of extraction intensification, purification method, and also the drying method was revealed.

In this diagram (Figure 1), the influence of the extraction parameters on the content of ballast substances is observed. As can be seen from the diagram, in the ratio of $\mathrm{Si}$, an inverse relationship is observed, with a decrease in the content of Shilajit raw in the solution, the content of $\mathrm{Si}$ increases. In relation to $\mathrm{Al}$, this dependence is not observed, but with an increase in the amount of solvent, the Al content is higher in the samples that were subjected

How to cite this article: Bugaev F, Kompantsev D, Pogrebnyak L. Optimization of the conditions of the extraction and purification stages of the Shilajit substance. J Res Pharm. 2019; 23(4): 697-700. 
to ultrasonic treatment. Based on the data obtained, the optimal ratio of raw materials (Shilajit) and extractant is 1: 2 without the use of ultrasound, since this ratio has the minimum content of ballast substances.

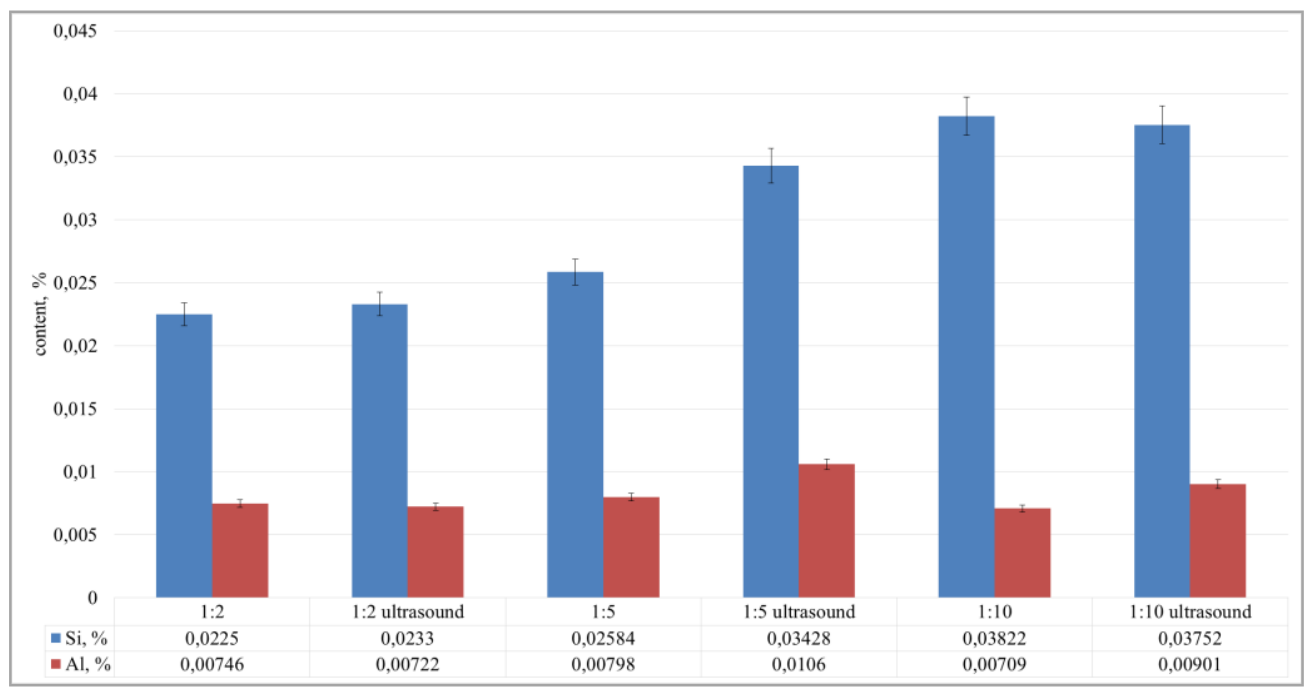

Figure 1. The effect of the ratio of extraction and ultrasonic treatment on the content of $\mathrm{Si}$ and $\mathrm{Al}$ in purified Shilajit using centrifugation. The data are expressed as mean \pm SD. Student's t-test was used for statistical analysis $\mathrm{p}<0.05, \mathrm{~N}=9$.

From the data obtained in the diagram (Figure 2), it can be concluded that the drying method has made a significant effect on the content of ballast substances in the final product. When applying the spray drying method, the content of ballast substances was significantly reduced, both Si and Al. Based on the data obtained, it was concluded that the use of the spray drying method in the technological process of obtaining Shilajit purified also leads to a decrease in the content of ballast substances in the final product.

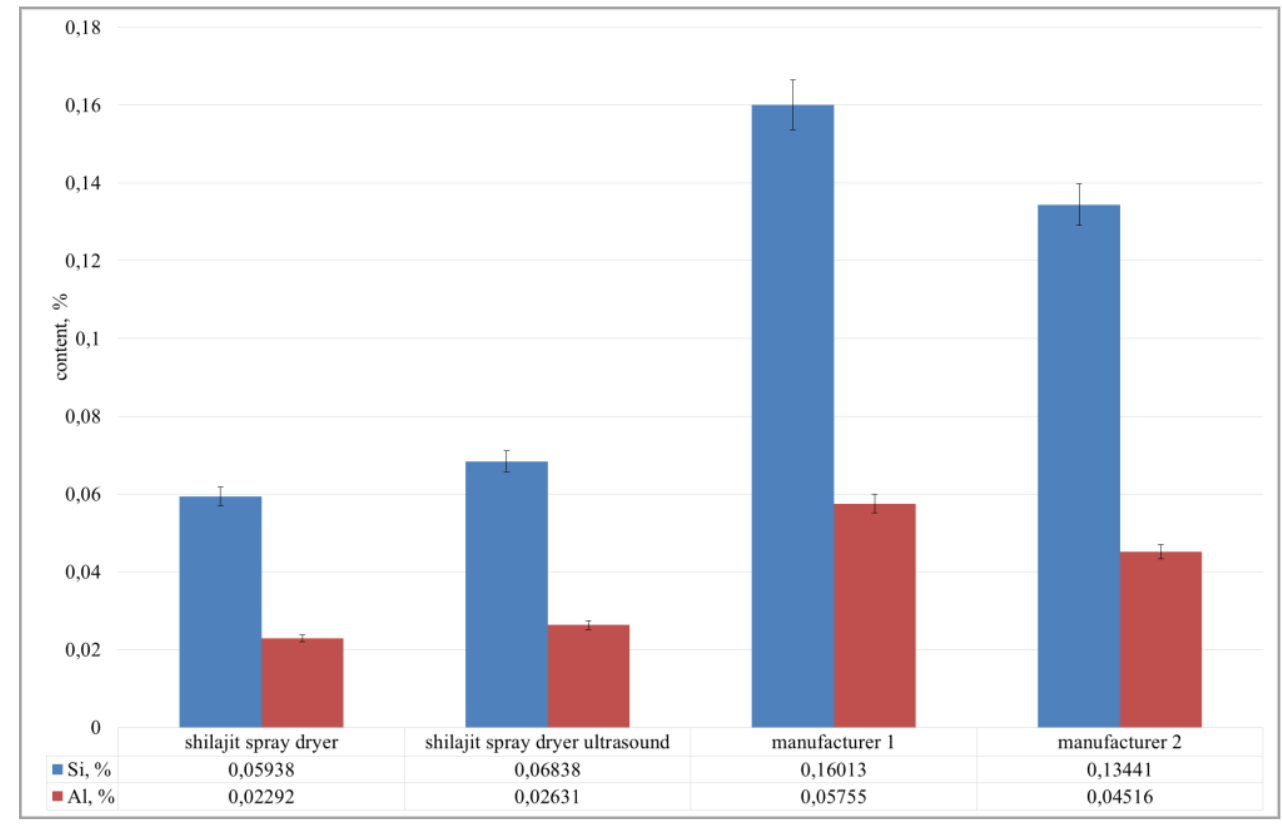

Figure 2. The effect of spray drying and ultrasonic processing on the content of $\mathrm{Si}$ and $\mathrm{Al}$ in purified Shilajit without the use of centrifugation in comparison with Shilajit obtained from the manufacturer 1 and 2 . The data are expressed as mean $\pm S D$. Student's t-test was used for statistical analysis $p<0.05, N=9$.

Also on the presented diagrams (Figure 1, Figure 2), the effect of ultrasonic treatment of the solution on the extraction stage is observed. The data presented show that the use of ultrasonic treatment for 1 hour significantly 
increases the Si content, and also slightly increases the $\mathrm{Al}$ content, on the basis of which ultrasonic treatment is not suitable for intensifying this process.

According to the obtained data in the diagram (Figure 3), it can be concluded that the use of the centrifugation process as one of the technological stages, namely, the stage of purification of the Shilajit solution from ballast substances is expedient since it reduces the content of $\mathrm{Si}$ and $\mathrm{Al}$ by $6-7$ times.

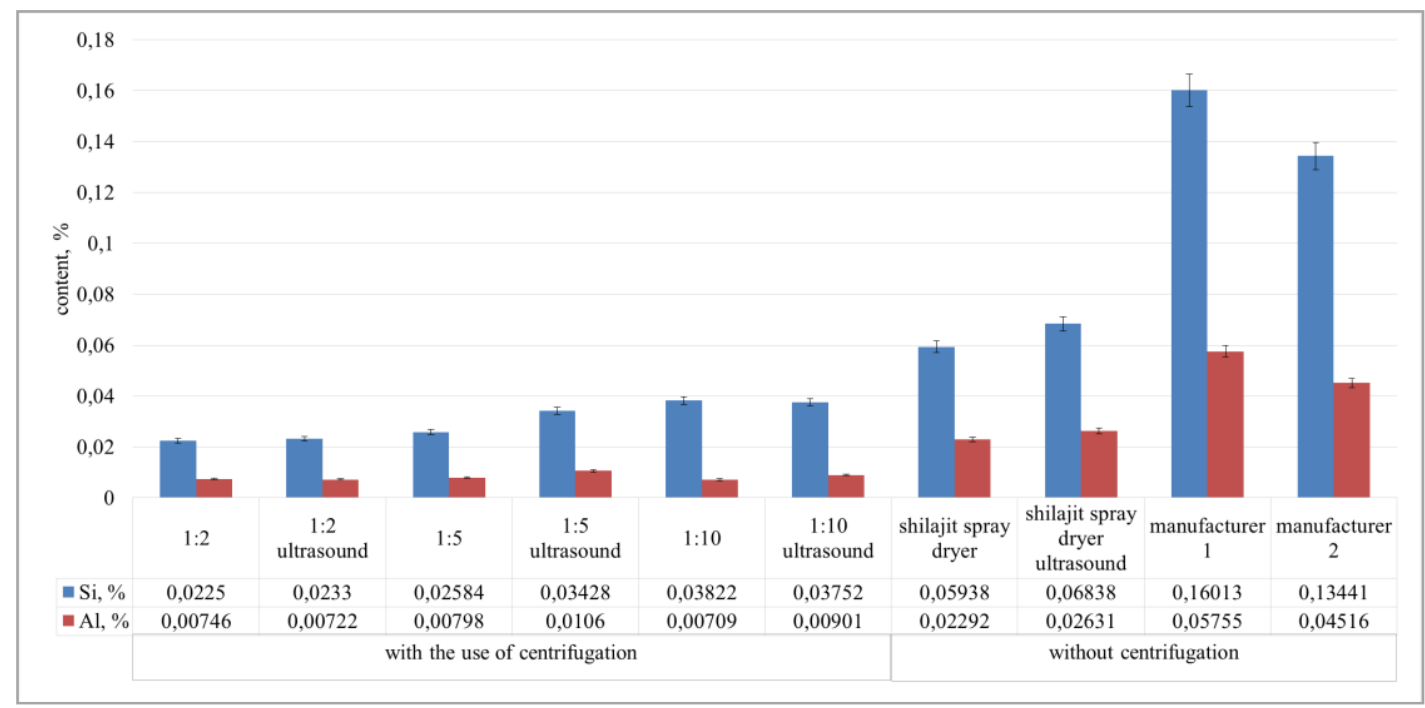

Figure 3. Summary diagram. The data are expressed as mean \pm SD. Student's t-test was used for statistical analysis $\mathrm{p}<0.05, \mathrm{~N}=9$.

\section{CONCLUSIONS}

$i$. The optimal ratio of raw material (Shilajit) and extractant is 1:2 without the use of ultrasound because, at this ratio, the minimum content of ballast substances was observed;

ii. The use of a centrifuge in the process of solution purification from ballast substances significantly reduces the content of $\mathrm{Al}$ and $\mathrm{Si}$;

iii. Application of the spray drying method in the technological process of obtaining Shilajit also leads to a decrease the content of ballast substances in the final product.

\section{MATERIALS AND METHODS}

For the experiment, samples of raw Shilajit, provided by Fitokom Altai LLC, were taken. The resulting purified Shilajit was produced using the following technologies:

$i$. The raw Shilajit was extracted with water in a ratio of $1: 2,1: 5,1: 10$ for 2 hours at a temperature of $20{ }^{\circ} \mathrm{C}$, stirring every 15 minutes. The resulting solution was centrifuged for 15 minutes at $5000 \mathrm{rpm}$. After that, the resulting supernatant was dried in a dry oven at temperature $70^{\circ} \mathrm{C}$ until a residual moisture content $5-10 \%$.

ii. The raw Shilajit was extracted with water in a ratio of 1:2, 1: 5, 1:10 for 2 hours at a temperature of $20^{\circ} \mathrm{C}$, stirring every 15 minutes. The solution was subjected to ultrasonic treatment with a converter frequency of 40 $\mathrm{kHz}$ for 1 hour. The resulting solution was centrifuged for 15 minutes at $5000 \mathrm{rpm}$. The resulting supernatant was dried in a dry oven at temperature $70^{\circ} \mathrm{C}$ until a residual moisture content $5-10 \%$.

iii. The raw Shilajit was extracted with water in a ratio of $1: 5$ for 2 hours at a temperature of $20^{\circ} \mathrm{C}$, stirring every 15 minutes. The resulting solution was dried using a spray dryer under the following conditions: the Shilajit solution is fed into the spray chamber under a pressure of 3-5 atm., the air temperature supplied to the upper part of the apparatus is not more than $140{ }^{\circ} \mathrm{C}$, the air temperature withdrawn from the lower part of the apparatus is at least $80^{\circ} \mathrm{C}$.

$i v$. The raw Shilajit was extracted with water in a ratio of $1: 5$ for 2 hours at a temperature of $20^{\circ} \mathrm{C}$, stirring every 15 minutes. The solution was subjected to ultrasonic treatment with a converter frequency of $40 \mathrm{kHz}$ for 1 hour. The resulting solution was dried using a spray dryer under the following conditions: the Shilajit solution is 
fed into the spray chamber under a pressure of 3-5 atm., the air temperature supplied to the upper part of the apparatus is not more than $140{ }^{\circ} \mathrm{C}$, the air temperature withdrawn from the lower part of the apparatus is at least $80^{\circ} \mathrm{C}$.

v. For comparison, two samples of industrial purified Shilajit were taken: manufacturer No. 1 - Laba Altai LLC, manufacturer No. 2 - Fitokom Altai LLC. Samples are presented in the form of plates; the moisture content of the samples is $7 \pm 2.5 \%$. These samples were purchased at retail pharmacies. From the appearance of the samples presented, it can be concluded that these samples were dried without the aid of a spray dryer.

For the samples obtained, a complete elemental analysis was performed on the S8 Tiger Wave X-ray fluorescence spectrometer. For the analysis, samples of Shilajit were selected using the method of quarrying of a sample weighing $4 \mathrm{~g}$. and filled in a cell with a polymer film (Mylar). Then the cuvettes are placed in cuvette holders, which are installed in the sampling device of the spectrometer. The measurements were carried out in vacuum using the software QUANT EXPRESS with the matrix - $\mathrm{CH} 2$ (organic compounds). Processing of the results was carried out using the developed methods in the program Spectra Plus (Bruker AXS GmbH, Germany) organic. The calculation of the content of the elements is made on absolutely dry matter.

Author contributions: Concept - F.B., D.K., L.P.; Design - F.B., D.K.; Supervision - F.B.; Materials -D.K.; Data Collection and/or Processing - F.B., D.K.; Analysis and/or Interpretation - F.B., D.K., L.P.; Literature Search - F.B., L.P.; Writing - F.B.; Critical Reviews - F.B., D.K., L.P.

Conflict of interest statement: The authors declared no conflict of interest.

\section{REFERENCES}

[1] Wilson E, Rajamanickam GV, Dubey GP, Klose P, Musial F, Saha FJ, Rampp T, Michalsen A, Dobos GJ. Review on shilajit used in traditional Indian medicine. J Ethnopharmacol. 2011; 136(1): 1-9. [CrossRef]

[2] Stohs SJ. Safety and Efficacy of Shilajit (Mumie, Moomiyo). Phytother Res. 2013; 28(4): 475-479. [CrossRef]

[3] Carrasco-Gallardo C, Guzmán L, Maccioni RB. Shilajit: A natural phytocomplex with potential procognitive activity. Int J Alzheimers Dis. 2012; 674142, 4 pages. [CrossRef]

This is an open access article which is publicly available on our journal's website under Institutional Repository at http://dspace.marmara.edu.tr. 